Vecuronium, which has failed to show any propensity for histamine release, also offers cardiovascular stability and would appear to offer theoretical advantages over atracurium in this group of patients.

Pinderfields General Hospital,

J.L. BEMBRIDGE Aberford Road, Wakefield.

West Yorkshire WF1 4DG

\section{References}

1. Basta SJ, Savarese JJ, Ali HH, Moss J, Guibfruddo M. Histamine-releasing potencies of atracurium besylate (BW 33a), metrocurine and d-tubocurarine. Anesthesiology 1982; 57: A261.

2. Sheps SG, Maher FT. Histamine and glucagon tests in diagnosis of pheochromocytoma. Journal of the American Medical Association 1968; 205: 895-9.

\title{
Marcain shakes
}

This is a well known, innocuous complication of epidural block, observed most frequently among labouring women and those undergoing Caesarean section. The appelation Marcain is misleading, since the syndrome can arise when local anaesthetics other than bupivacaine are used.

The shaking can start at the beginning, or midway through the period of block and can stop before or at the conclusion of the effectiveness of the epidural. The cause has not yet been determind. Several hypotheses have been presented; the most recent is that it is due to stimulation of thermoreceptors in the spinal canal by the injection of relatively cold solution of local anaesthetic. ${ }^{1}$

We have encountered two cases of unilateral shakes during recent years, one mild and one disturbingly severe. In each case an ipsilateral arm, leg and (probably) trunk was involved; the shaking persisted throughout the period of epidural analgesia provided for labour. The agent used was plain bupivacaine. Both mothers had excellent bilateral analgesia and weakness of both legs. The observations made during labour were emphatically confirmed by the respective mothers during the routine interview on the day following delivery.

I am totally at a loss to explain this phenomenon. Realistic suggestions would be welcomed.

The Birmingham Maternity Hospital, J.S. CRAWFORD Birmingham B15 2TG

\section{Reference}

1. Walmsley AJ, Giesecke AH, Lipton JM. Epidural temperature: a cause of shivering during epidural anesthesia. Anesthesia and Analgesia 1986; 65: S164.

\section{Test doses for epidural analgesia—are we fooling ourselves?}

In Dr J.S. Crawford's review article on complications of epidural analgesia for labour (Anaesthesia 1985; 40: 1219-25) it is disturbing to note that in none of the potentially life threatening or moderately serious complications was an appropriate test does used before epidural analgesia was established. A test dose prior to a full dose should forewarn the operator of both intravascular and subarachnoid placement of the epidural catheter. Unfortunately, $2 \mathrm{ml} 1 \%$ lignocaine does not reliably produce a sensory block when injected into the subarachnoid space, particularly if it is isobaric, nor does it give any guide to intravascular injection.

A reliable test dose of any local anaesthetic should include $15 \mu \mathrm{g}$ adrenaline which has consistently been shown to cause a tachycardia within one minute of intravenous injection when given with either lignocaine or bupivacaine. ${ }^{1}$ For the local anaesthesia component either $0.5 \%$ bupivacaine or $1.5 \%$ of hyperbaric lignocaine may be used. Three millilitres $0.5 \%$ isobaric or hyperbaric bupivacaine reliably produces some analgesia within 5 minutes of subarachnoid injection, ${ }^{2}$ but little effect is likely to be seen with epidural injection within 2 minutes if injected into the subarachnoid space, but takes a minimum of 4 minutes (mean 9 minutes) to produce any sensory blockage when given into the epidural space. ${ }^{3}$

Unless an epidural test dose contains both an appropriate volume and concentration of local anaesthetic (either $3 \mathrm{ml} 0.5 \%$ bupivacaine or $2 \mathrm{ml} 1.5 \%$ hyperbaric lignocaine) plus a minimum of $15 \mu \mathrm{g}$ of adrenaline, it will not warn the operator of inadvertent subarachnoid or intravascular injection. Only if the above criteria are satisfied may an epidural test offer any warning of potential problems.

\section{Department of Anesthesiology,}

N.C.T. WILTON University of Michigan Hospitals. 1500 E. Medical Center Drive, Room IG323 Box 0048, Ann Arbor, Michigan 48109, USA

\section{References}

1. MoORe DA, Batsa MS. The components of an effective test dose prior to epidural block. Anesthesiology 1981; 55: 693-6.

2. Chambers WA, Edstrom HH, Scott DB. Effect of baricity on spinal anaesthesia with bupivacaine. British Journal of Anaesthesia 1981; 53: 279-82.

3. Abraham RA. Harris ap, Maxwell lg, Kaplow S. The 
efficacy of $1.5 \%$ lidocaine with $7.5 \%$ dextrose and epinephrine as an epidural test dose for obstetrics. Anesthesiology' 1986; 64: 116.9.

\section{A reply}

May I point out that the data from which my report was compiled were collected during an 18-year period of clinical observations. During that time, and before it, a multiplicity of test doses have been advocated; these range from the inclusion of $5 \mathrm{mg}$ suxamethonium in the solution (referred to by Massey Dawkins in his comprehensive review, ${ }^{1}$ ) to the currently strongly supported use of adrenaline. The very fact of this bewildering number of contenders strengthens my conviction that none is truly reliable. No single test has, to my knowledge, been convincingly demonstrated to be infallible within a large series of cases.

The current, and in my opinion admirable advocacy that all therapeutic injections into the epidural space should be in divided doses (for example, $5+5 \mathrm{ml}$ for an intended $10 \mathrm{ml}$ top-up) renders the advocacy of a $5 \mathrm{ml}$ test dose somewhat questionable, since the function of one is taken over by the other. One is disinclined to include adrenaline in the injected solution. The plain solution of bupivacaine has a $\mathrm{pH}$ value of approximately 6 , that of bupivacaine plus adrenaline lies between 3 and $4,{ }^{2}$ and I am reluctant to put such an acidic solution close to naked nerve fibres within the cerebrospinal fluid. Furthermore, a high percentage of patients in obstetric analgesia practice are hypertensive. The prospective of an inadvertent intravenous injection of adrenaline in these women would cause me grave concern. Other practitioners hold contrary views, which I respect, but they are simply another expression of unsubstantiated opinion.

During the period reviewed in my article our test dose has consisted predominantly of $2 \mathrm{ml}$ plain lignocaine. 0.5 or $1.0 \%$. Occasionally a mother will report tingling of her tongue or perioral region, or some dizziness subsequent to this injection; very rarely hypotension has resulted, or a feeling of leg heaviness. The practice is continued, more in obeisance to tradition than for any other reason, although it is my opinion that it is useful to ensure that there is no obstruction to the flow of solution within the catheter and that the latter does not become clogged by the deposition of proteinaceous material whilst dressings are applied.

Doubtless this will offend many of your readers as being a negative attitude. Two things I am positive about: I will never subscribe to the practice of injecting a test dose through the needle and then of inserting the catheter, followed by a formal dose through the latter. Secondly, it is of incomparably greater importance to be able promptly to institute the appropriate resuscitation, should an injection be inadvertently made intravenously or intrathecally, than it is to employ any of the advocated techniques of test dosing.

The Birmingham Maternity Hospital, J.S. CRAWFORD Birmingham B15 $2 T G$

\section{References}

1. Dawkins CJM. An analysis of the complications of extradural and caudal block. Anaesthesia 1969; 24: 554-63.

2. Bromage PR. An evaluation of bupivacaine in epidural analgesia for obstetrics. Canadian Anaesthetists' Society Journal 1969: 16: 46-56.

\section{Iatrogenic hypotension}

Percutaneous catheterisation of the radial artery is a standard procedure for peri-operative intra-arterial blood pressure monitoring of adults undergoing cardiopulmonary bypass surgery.

A patient presented for aortocoronary vein grafting. Intra-arterial monitoring was established using a 20gauge Argyle medicut cannula inserted into the left radial artery. The patient remained stable during retraction of the sternum and elevation of the pericardium, until immediately prior to aortic cannulation. The systolic blood pressure decreased to $50 \mathrm{mmHg}$ and the arterial waveform developed the characteristics of a damped trace at this time. The monitored blood pressure remained low, despite fluid loading and intravenous calcium chloride. Cardiopulmonary bypass perfusion was established without delay.

The displayed radial artery pressure when bypass was established was $30 \mathrm{mmHg}$, with a flattened trace, while the aortic line pressure was $180 \mathrm{mmHg}$. It was felt that the radial artery pressure was inaccurate. The trans- ducer was recalibrated and there was free aspiration of arterial blood from the line; repositioning of the left hand did not affect the waveform and the left hand was clinically well perfused. The aortic pressure, measured directly via a 21 -gauge needle and connected to the same transducer, was $60 \mathrm{mmHg}$ and so this pressure was monitored during cardiopulmonary bypass perfusion.

When the graft was in place cardiopulmonary bypass was withdrawn and the circulation was re-established. However, the discrepancy between aortic and radial artery pressures persisted. When the sternal retractor was released, the radial artery pressure tracing returned to normal and the difference disappeared.

Hypotension in the period prior to cardiopulmonary bypass is not uncommon. This may be due to a poorly contracting ventricle, blood loss, lifting of the pericardium or may be consequent upon rhythm disturbances. None of these factors was contributory to the hypotension seen in this patient. However, immediately prior to cannulation, the sternal retraction had been 